\title{
Four novel Talaromyces species isolated from leaf litter from Colombian Amazon rain forests
}

\author{
Neriman Yilmaz ${ }^{1,2,3}$ • Carlos A. López-Quintero ${ }^{4}$ Aída Marcela Vasco-Palacios ${ }^{1,5}$. \\ Jens C. Frisvad ${ }^{6}$ - Bart Theelen ${ }^{1}$ - Teun Boekhout ${ }^{1} \cdot$ Robert A. Samson $^{1}$. \\ Jos Houbraken ${ }^{1}$
}

Received: 29 April 2016/Accepted: 7 September 2016 /Published online: 22 October 2016

(C) The Author(s) 2016. This article is published with open access at Springerlink.com

\begin{abstract}
Various Talaromyces strains were isolated during a survey of fungi involved in leaf litter decomposition in tropical lowland forests in the Caquetá and Amacayacu areas of the Colombian Amazon. Four new Talaromyces species are described using a polyphasic approach, which includes phenotypic characters, extrolite profiles and phylogenetic analysis of the internal transcribed spacer region (ITS) barcode, and betatubulin $(B e n A)$ and calmodulin $(\mathrm{CaM})$ gene regions. Talaromyces amazonensis sp. nov., T. francoae sp. nov. and T. purgamentorum sp. nov. belong to Talaromyces section Talaromyces, and T. columbiensis sp. nov. is located in section Bacillispori. The new species produce several bioactive compounds: T. amazonensis produces the potential anticancer agents
\end{abstract}

Section Editors: Pedro W. Crous and Roland Kirschner

This article is part of the Special Issue "Biodiversity of Hyphomycetes - Special Issue in honor of Dr. Subramanian".

Jos Houbraken

j.houbraken@cbs.knaw.nl

1 CBS-KNAW Fungal Biodiversity Centre, Uppsalalaan 8, 3584 CT Utrecht, The Netherlands

2 Department of Biology, University of Ottawa, 30 Marie-Curie, Ottawa, Ontario K1N 6N5, Canada

3 Biodiversity (Mycology), Ottawa Research and Development Centre, Agriculture \& Agri-Food Canada, 960 Carling Ave., Ottawa, Ontario K1A 0C6, Canada

4 Laboratorio de Taxonomía y Ecología de Hongos (TEHO), Instituto de Biología, Universidad de Antioquia, PO Box 1226, Calle 67 \# 53-108, Medellin, Colombia

5 Fundación Biodiversa Colombia, Carrera 22 \# 41-80 Apto. 004, 111311 Bogotá, D.C., Colombia

6 Center for Microbial Biotechnology, Department of Systems Biology, Technical University of Denmark, Kgs. Lyngby, Denmark duclauxin, berkelic acid and vermicillin, and T. columbiensis produces the effective anticancer agent wortmannin (together with duclauxin). In addition to the new species, T. aculeatus and T. macrosporus were isolated during this study on leaf litter decomposition.

Keywords Taxonomy · Phylogeny · Bioactive compounds · Plant biomass degradation

\section{Introduction}

Fungi play an important role in forest ecosystems, as they are involved in processes such as decomposition of leaf litter. Leaf decomposition contributes to nutrient cycling, in which a large proportion of nutrients from net primary production is returned to the forest floor (Maggs 1985). A number of papers have recently been published on fungal biodiversity in the Colombian Amazon region, reporting new species and new registers. Studies in this region revealed 248 species of macrofungi, but a large number of collections have remained unidentified (López-Quintero et al. 2012; Vasco-Palacios and Franco-Molano 2013). Several new taxa of micro- and macrofungi have been published - for instance, new species of Penicillium and Trichoderma (Houbraken et al. 2011; López-Quintero et al. 2013; VascoPalacios and Franco-Molano 2013; Vasco-Palacios et al. 2014).

Talaromyces species have a worldwide distribution and are isolated from a wide range of substrates. The genus was initially described for teleomorphic species with a Penicillium or Penicillium-like anamorph that produces soft-walled ascomata covered by interwoven hyphae. Based on phylogenetic, phenotypic and extrolite data, and following the concept of single-name nomenclature, Samson et al. (2011) transferred all accepted species of Penicillium subg. Biverticillium to Talaromyces. The Talaromyces monograph of Yilmaz et al. 
(2014) covered 88 species, and the genus currently includes 103 species (Visagie et al. 2015; Romero et al. 2016; Wang et al. 2016; Yilmaz et al. 2016).

Numerous microfungi were isolated from decomposing leaf litter as part of a project to investigate their diversity and their role in the regeneration process of tropical lowland forests. Barcoding using ITS sequences (Schoch et al. 2012) revealed the presence of several Talaromyces species, and their taxonomic status is the subject of this report. Four new species are proposed and described using a polyphasic taxonomy, which includes phenotypic characters, analysis of extrolites and multiple gene phylogenies of internal transcribed spacer region (ITS), beta-tubulin (BenA) and calmodulin $(\mathrm{CaM})$ gene regions.

\section{Material and methods}

\section{Strains}

The strains were isolated from leaf litter as described in Houbraken et al. (2011). In short, small particles from fresh or 4-6 month-old leaf litter were washed and placed on $2 \%$ water agar. The strains were obtained from three forests in Colombia Amazonia, namely mature forests in Araracuara (Middle Caquetá) and Amacayacu (Amazonas), and a Pseudomonotes tropenbosii (Dipterocarpaceae) forest in Peña Roja (Middle Caquetá). The litterbag studies were carried out during February 2000 and July 2001 for the plots located in the Caquetá region and between August 2003 and September 2004 in the plots located in the Amazonas. The newly obtained isolates and strains used for comparison are listed in Table 1, together with their origin, substrate information and GenBank accession numbers for ITS, BenA and CaM genes. Strains of the putative new Talaromyces species used in this study were deposited in the culture collection of CBS-KNAW Fungal Biodiversity Centre, Utrecht, the Netherlands; the Center for Microbial Biotechnology at the Department of Systems Biology, Technical University of Denmark, Lyngby, Denmark (IBT); and the working collection of the Department of Applied and Industrial Mycology (DTO), housed at CBSKNAW. The type material of the new taxa is preserved at the herbarium of the University of Antioquia (HUA).

\section{DNA extraction, PCR amplification and sequencing}

DNA extractions were made from strains grown for 7-14 days on MEA using the UltraClean ${ }^{\circledR}$ Microbial DNA Isolation Kit (MO BIO Laboratories, Carlsbad, CA, USA), and extracted DNA was stored at $-20^{\circ} \mathrm{C}$. ITS, $C a M$ and $B e n A$ gene regions were amplified and sequenced using previously described methods (Visagie et al. 2014; Yilmaz et al. 2014).

\section{Phylogeny}

Sequence contigs were assembled in SeqMan v. 9.0.4 (DNASTAR, Inc., Madison, WI, USA). The newly generated sequences were included in a data set including sequences obtained from Yilmaz et al. (2014) and supplemented with sequences of new species that were subsequently described (Visagie et al. 2015; Wang et al. 2016; Yilmaz et al. 2016). The dataset for each gene was aligned using the MUSCLE software included in the MEGA v. 6.0.6 software package (Tamura et al. 2013). The aligned ITS, BenA and CaM data were analyzed using the maximum likelihood (ML) method. The model for ML was selected based on the Akaike information criterion (AIC) calculated in MEGA 6.06. The analysis was performed by calculating an initial tree using BIONJ, and the subsequent heuristic using Nearest-Neighbour-Interchange (NNI). Bootstrap support was calculated using 1000 replicates.

\section{Morphological analysis}

Strains were morphologically studied on different media under different growth conditions. Cultures were inoculated onto Czapek yeast extract agar (CYA), CYA supplemented with $5 \% \mathrm{NaCl}$ (CYAS), yeast extract sucrose agar (YES), creatine sucrose agar (CREA), dichloran $18 \%$ glycerol agar (DG18), oatmeal agar (OA) and malt extract agar (MEA; Oxoid malt) at three points on 90-mm Petri dishes and incubated for 7 days at $25{ }^{\circ} \mathrm{C}$ in darkness. All media were prepared as described by Visagie et al. (2014). Additional MEA and CYA plates were incubated at $30{ }^{\circ} \mathrm{C}$ and $37{ }^{\circ} \mathrm{C}$ for 7 days in darkness. After incubation, the diameters of the colonies on the various media were measured. The density of sporulation, obverse and reverse colony colours, and the production of soluble pigments were noted. Colony colour codes refer to Kornerup and Wanscher (1967). Colonies were photographed with a Canon EOS 400D camera. Species were characterized microscopically by preparing slides from MEA. Lactic acid was used as mounting fluid, and excess amounts of conidia were washed with ethanol. Specimens were examined using a ZEISS AxioSkop 2 plus microscope, and the Nikon NIS-Elements D software package was used for capturing photographs and taking measurements. Figure plates were prepared in Adobe ${ }^{\circledR}$ Photoshop ${ }^{\circledR}$ CS6.

\section{Extrolites}

The strains isolated during this study were analyzed by highperformance liquid chromatography (HPLC) with diode array detection as described by Houbraken et al. (2012). Three agar plugs from the Talaromyces isolates grown on CYA, MEA, YES and OA at $25^{\circ} \mathrm{C}$ for 7 days were extracted as described by Smedsgaard (1997). The detected metabolites were identified by comparison with standards according to Kildgaard et al. (2014) and Klitgaard et al. (2014). 


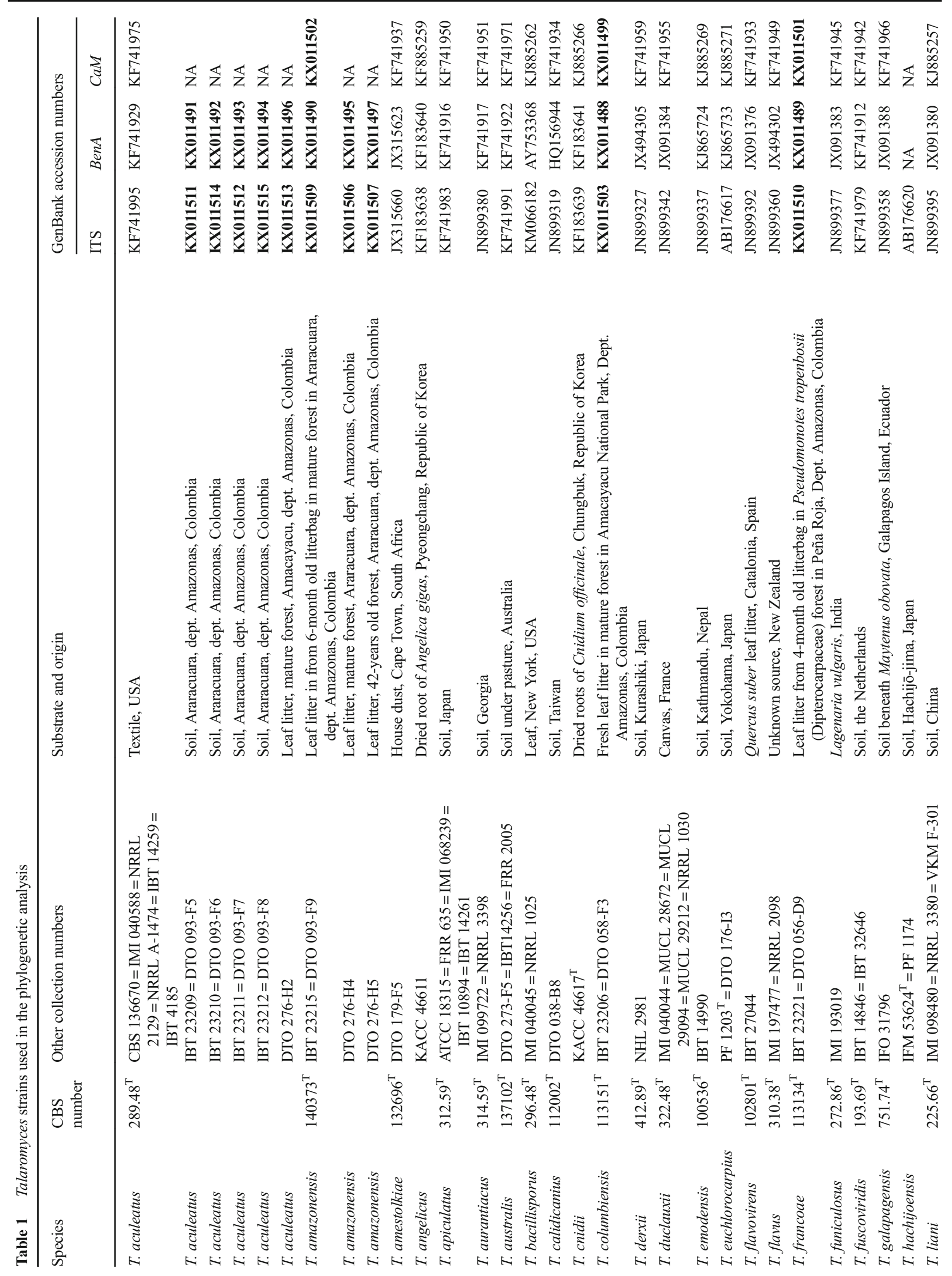




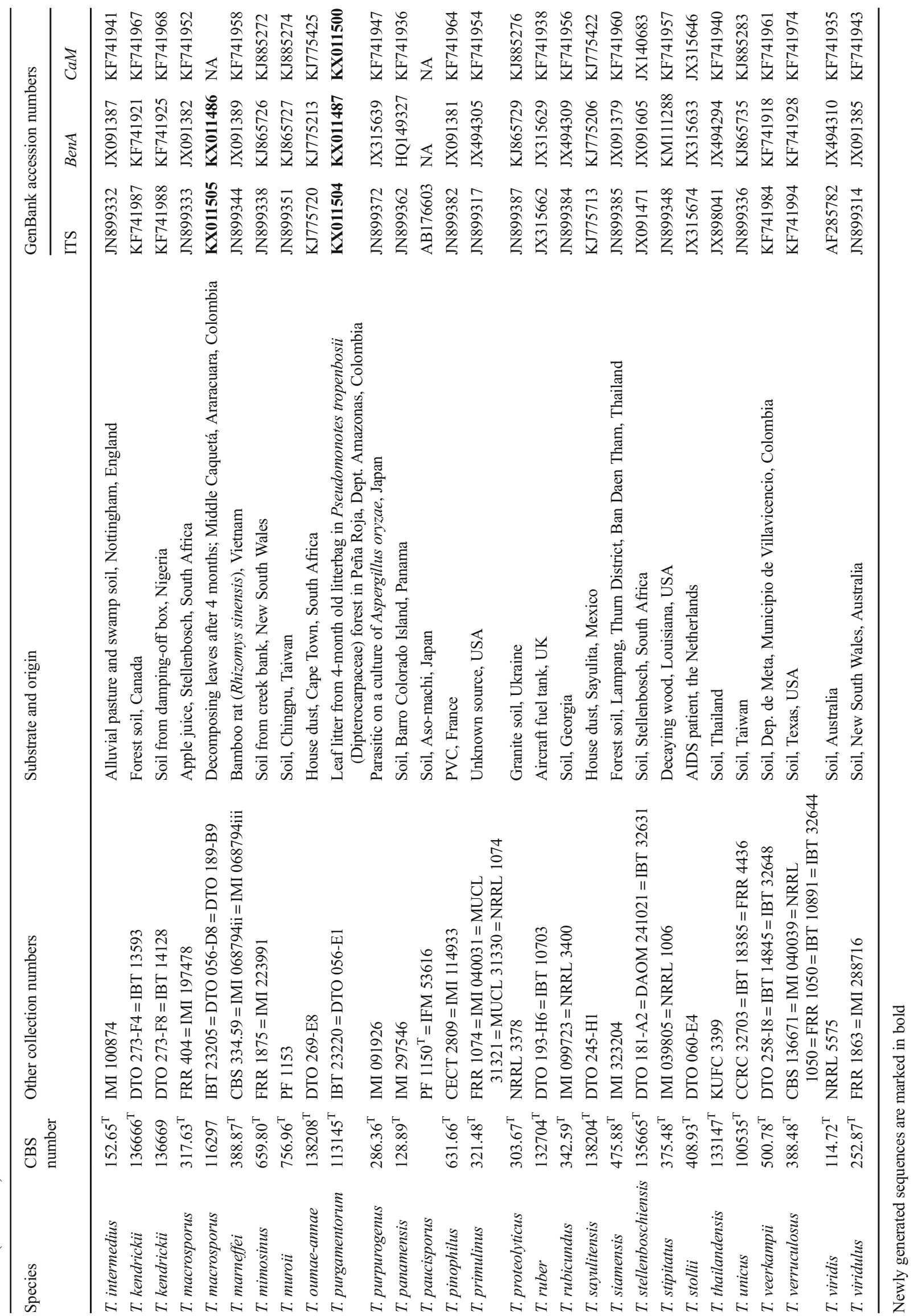




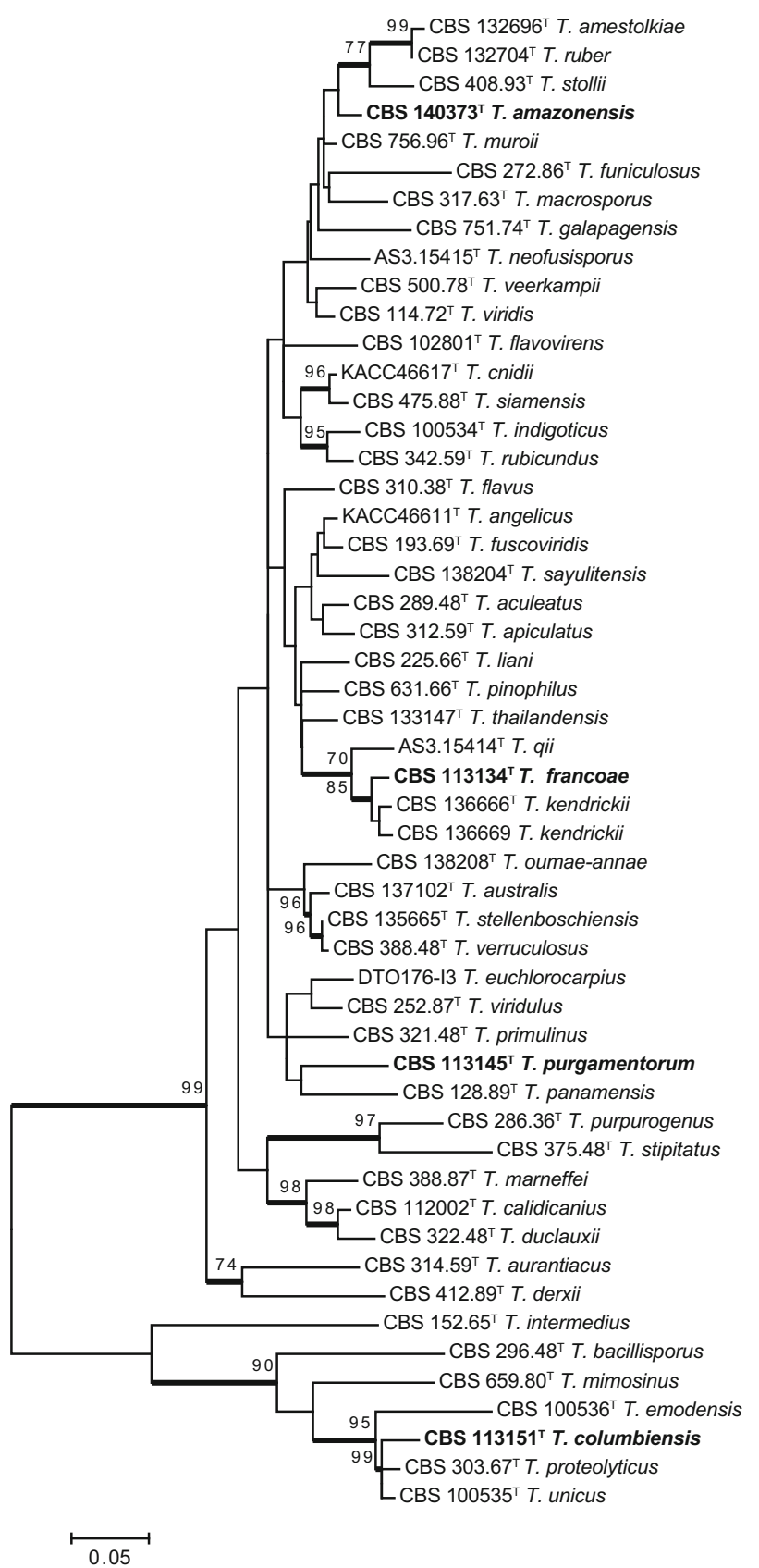

Fig. 1 Phylogenies based on the ITS, BenA, CaM and combined data set showing the relationship between the new species described in the study and other members of Talaromyces sections Talaromyces and Bacillispori. Strains of known species (T. aculeatus and T. macrosporus) isolated in the

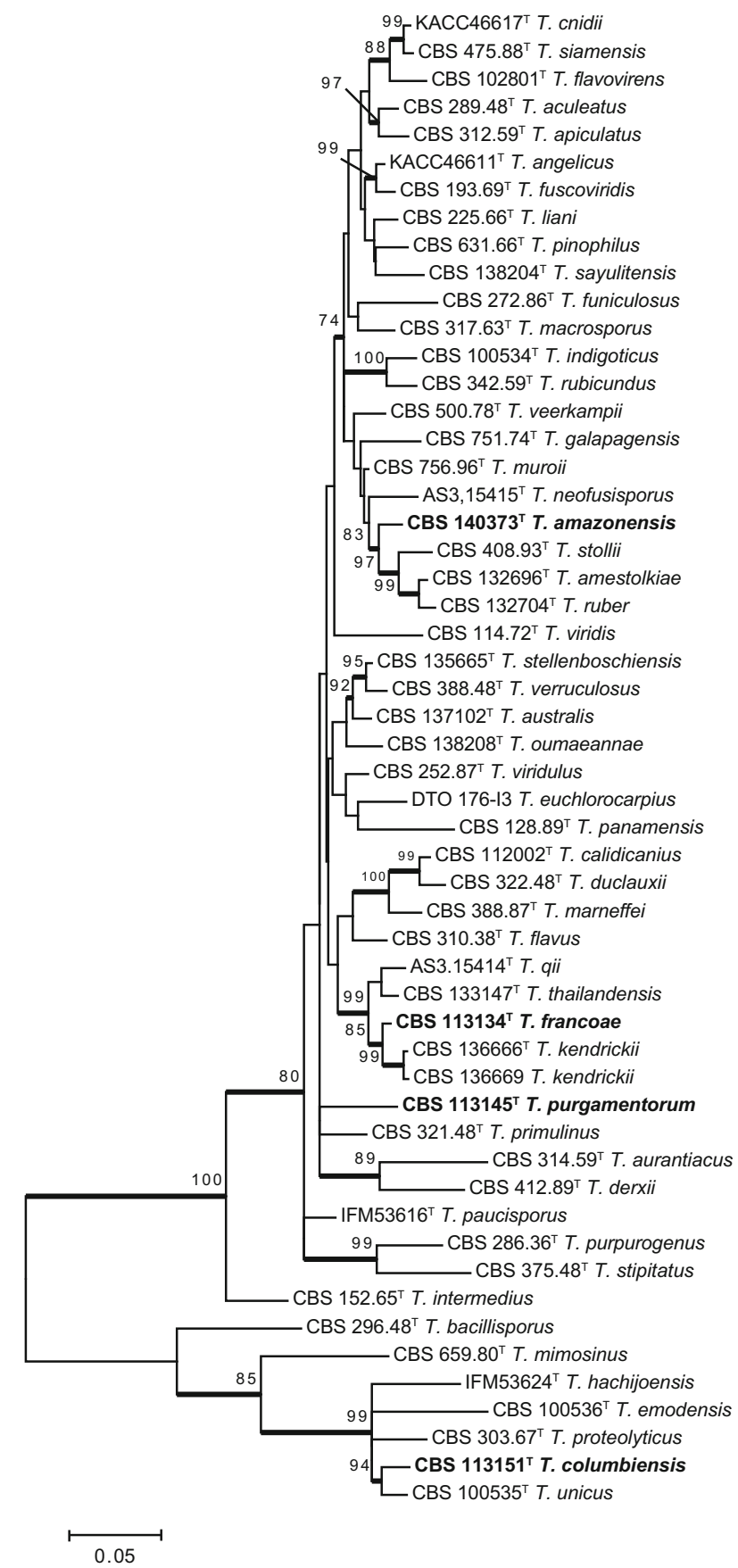

course of this study are marked with asterisks in ITS and BenA phylograms. Strains belonging to new species are indicated by bold text. Support in nodes are indicated by thickened branches for bootstrap values $\geq 70, \%$ and ${ }^{T}$ indicates ex-type strains 
ITS

100

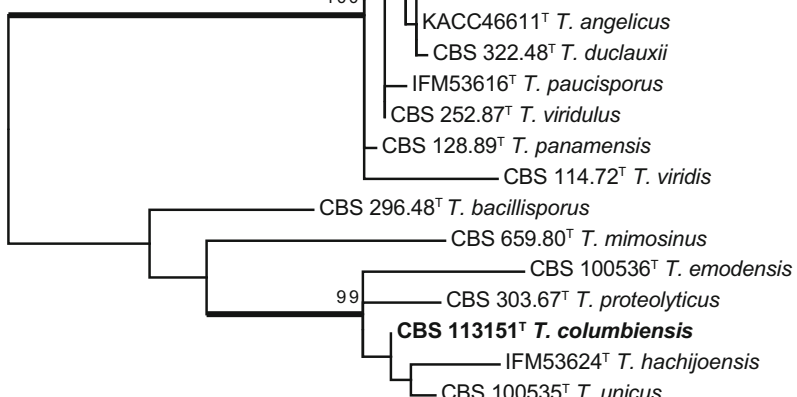

$\stackrel{\vdash}{0.02}$
CBS $631.66^{\top} T$. pinophilus

- CBS $138204^{\top}$ T. sayulitensis

— CBS $751.74^{\top} T$. galapagensis

—CBS 286.36 $T$. purpurogenus CBS $375.48^{\top} T$. stipitatus

- CBS $500.78^{\top} T$. veerkampii

CBS $225.66^{\top} T$. liani

CBS $756.96^{\top}$ T. muroii

- CBS $317.63^{\top}$ T. macrosporus

CBS 116297 T. macrosporus *

CBS $100534^{\top} T$. indigoticus

_ CBS 342.59 T. rubicundus

CBS $137102^{\top} T$. australis

CBS $475.88^{\top} T$. siamensis

- KACC46617 $T$. cnidi

- CBS $310.38^{\top} T$. flavus

CBS $113145^{\top} T$. purgamentorum

CBS $138208^{\top} T$. oumae-annae

AS3.15415 T. neofusisporus

CBS $135665^{\top}$ T. stellenboschiensis

DT0176-I3 T. euchlorocarpius

LCBS $321.48^{\top}$ T. primulinus

CBS $132696^{\top} T$. amestolkiae

LCBS $132704^{\top} T$. ruber

DTO 093-F5 T. aculeatus*

DTO 093-F6 T. aculeatus*

DTO 093-F7 T. aculeatus*

CBS $289.48^{\top} T$. aculeatus

DTO 276-H2 T. aculeatus *

- CBS $408.93^{\top} T$. stollii

DTO 093-F8 T. aculeatus *

—AS3.15414 T' T. qii

LCBS $388.87^{\top}$ T. marneffei

CBS $136666^{\top} T$. kendrickii

CBS 136669 T. kendrickii

- CBS $133147^{\top}$ T. thailandensis

CBS $113134^{\top} T$. francoae

CBS $312.59^{\top} T$. apiculatus

- CBS $152.65^{\top} T$. intermedius

CBS $140373^{\top} T$. amazonensis

DTO 276-H4 T. amazonensis

84 DTO 276-H5 T. amazonensis

DTO 276-H6 T. amazonensis

CBS $272.86^{\top} T$. funiculosus

CBS $314.59^{\top} T$. aurantiacus

- CBS $412.89^{\top} T$. derxii

CBS $112002^{\top} T$. calidicanius

CBS $102801^{\top} T$. flavovirens

- CBS 193.69' T. fuscoviridis

KACC $46611^{\top} T$. angelicus

L CBS $322.48^{\top} T$ duclauxil

- IFM53616 $T$. paucisporus

BS $252.87^{\top} T$. viridulus

$T$. panamensis

cillisporus

$59.80^{\top} T$ mimosinus IFM53624' T. hachijoensis

- CBS $100535^{\top} T$. unicus
CBS $388.48^{\top} T$. verruculosus
BenA

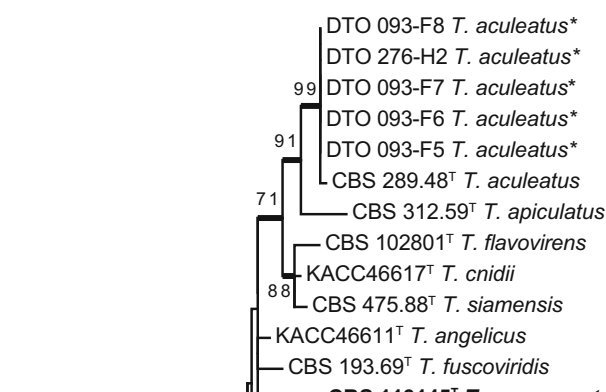

CB.69 T. fuscovidis

CBS $113145^{\top} T$. purgamentorum

CBS $500.78^{\top} T$. veerkampii

- CBS $138204^{\top} T$. sayulitensis

CBS $225.66^{\top} T$. liani

CBS $631.66^{\top} T$. pinophilus

CBS $751.74^{\top}$ T. galapagensis

96 اCBS $756.96^{\top}$ T. muroii

- AS3.15415 15 T. neofusisporus

- CBS $100534^{\top} T$. indigoticus

- CBS $342.59^{\top} T$. rubicundus

- CBS $132696^{\top} T$. amestolkiae

82 LBS $132704^{\top}$ T. ruber

- CBS $408.93^{\top} T$. stolli

DTO 276-H4 T. amazonensis

99 DTO 276-H5 T. amazonensis

DTO 276-H6 T. amazonensis

CBS $140373^{\top} T$, amazonensis

98 CBS 116297 T. macrosporus*

LCBS $317.63^{\top}$ T. macrosporus

${ }^{71}$ CBS $272.86^{\top}$ T. funiculosus

CBS $321.48^{\top}$ T. primulinus - CBS $114.72^{\top} T$. viridis

CBS $138208^{\top} T$. oumae-annae

[ $\left[\right.$ CBS $252.87^{\top} T$. viridulus

- CBS $137102^{\top} T$. australis

${ }^{C B S} 135665^{\top} T$. stellenboschiensis

CBS $388.48^{\top} T$. verruculosus $86 \longrightarrow$ CBS $286.36^{\top}$ T. purpurogenus

$\mathrm{AS}^{\mathrm{AS} .15414^{\mathrm{T}} T \text {. qii }}$ CBS $375.48^{\top} T$ stipitatus

LCBS $133147^{\top} T$ thailandensis

97 CBS 113134' T. francoae

99 CBS $136666^{\top}$ T. kendrickii

CBS 136669 T. kendrickii

- CBS $152.65^{\top} T$. intermedius CBS $128.89^{\top} T$. panamensis DTO176-I3 T. euchlorocarpius

- DTO ${ }_{85}^{95}{ }^{\text {CBS }} 112002^{\top}$ T. calidicanius
CBS $322.48^{\top}$ T. duclauxii

- CBS $310.38^{\top} T$. flavus

LCBS $388.87^{\top}$ T. marneffei

CBS $412.89^{\top} T$. derxii

CBS $314.59^{\top} T$. aurantiacus

CBS $296.48^{\top} T$. bacillisporus

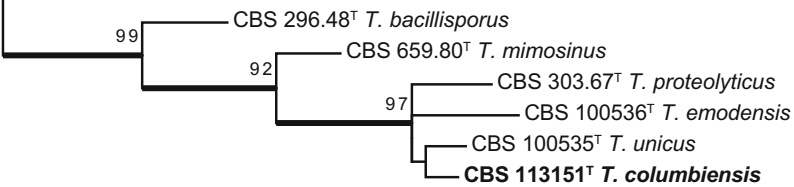

$\overline{0.05}$

Fig. 1 continued. 

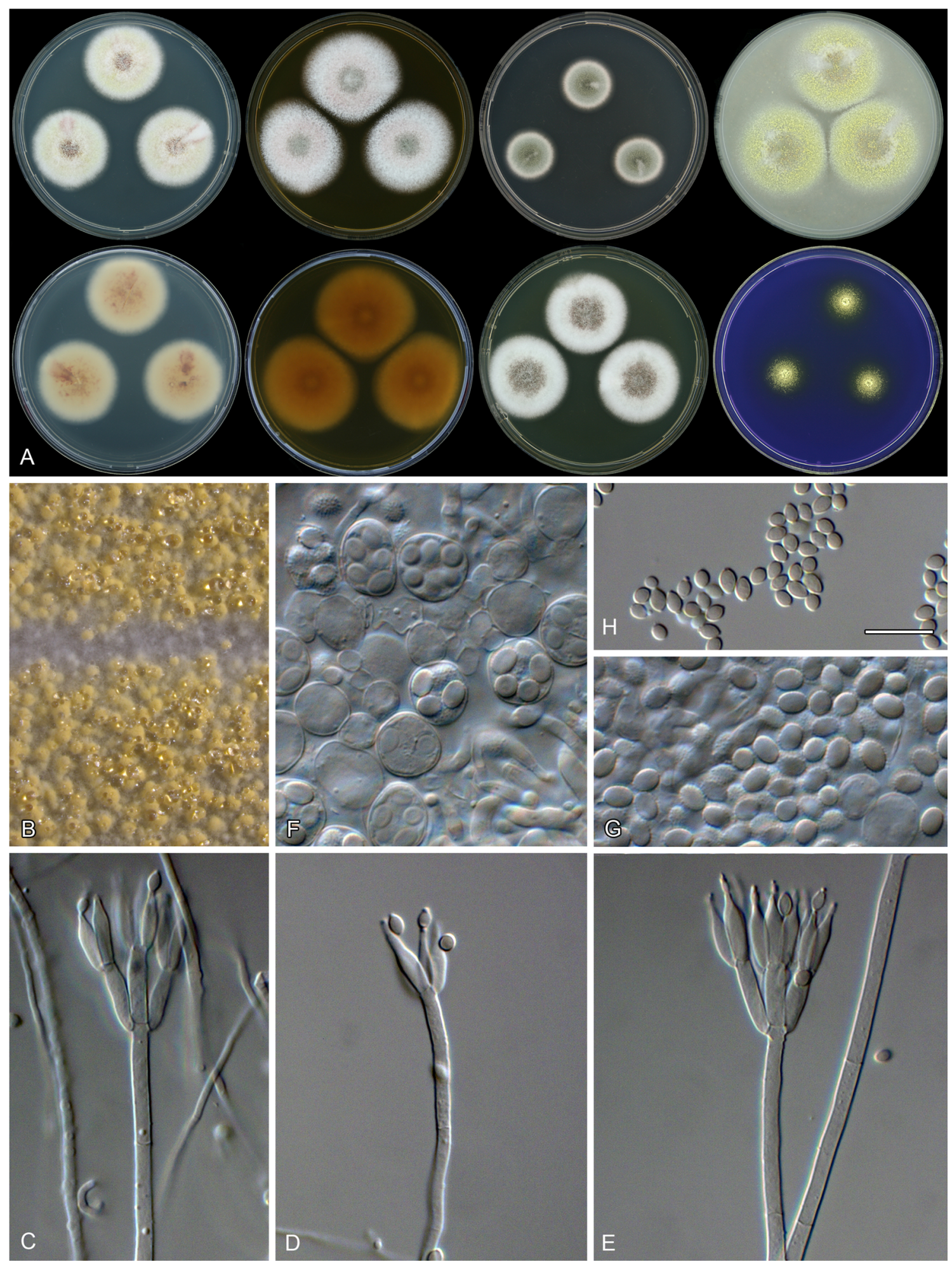
$140373^{\mathrm{T}}$ ). a Colonies from left to right (top row) CYA, MEA, DG18

Colony texture and ascomata on $\mathrm{OA}$ after 2 -week incubation. $\mathbf{c}-\mathbf{e}$ and OA; (bottom row) CYA reverse, MEA reverse, YES and CREA. b

Conidiophores. f Asci and ascospores. g Ascospores. h Conidia. Scale bar: $\mathbf{h}=10 \mu \mathrm{m}$ applies to $\mathbf{c}-\mathbf{h}$ 

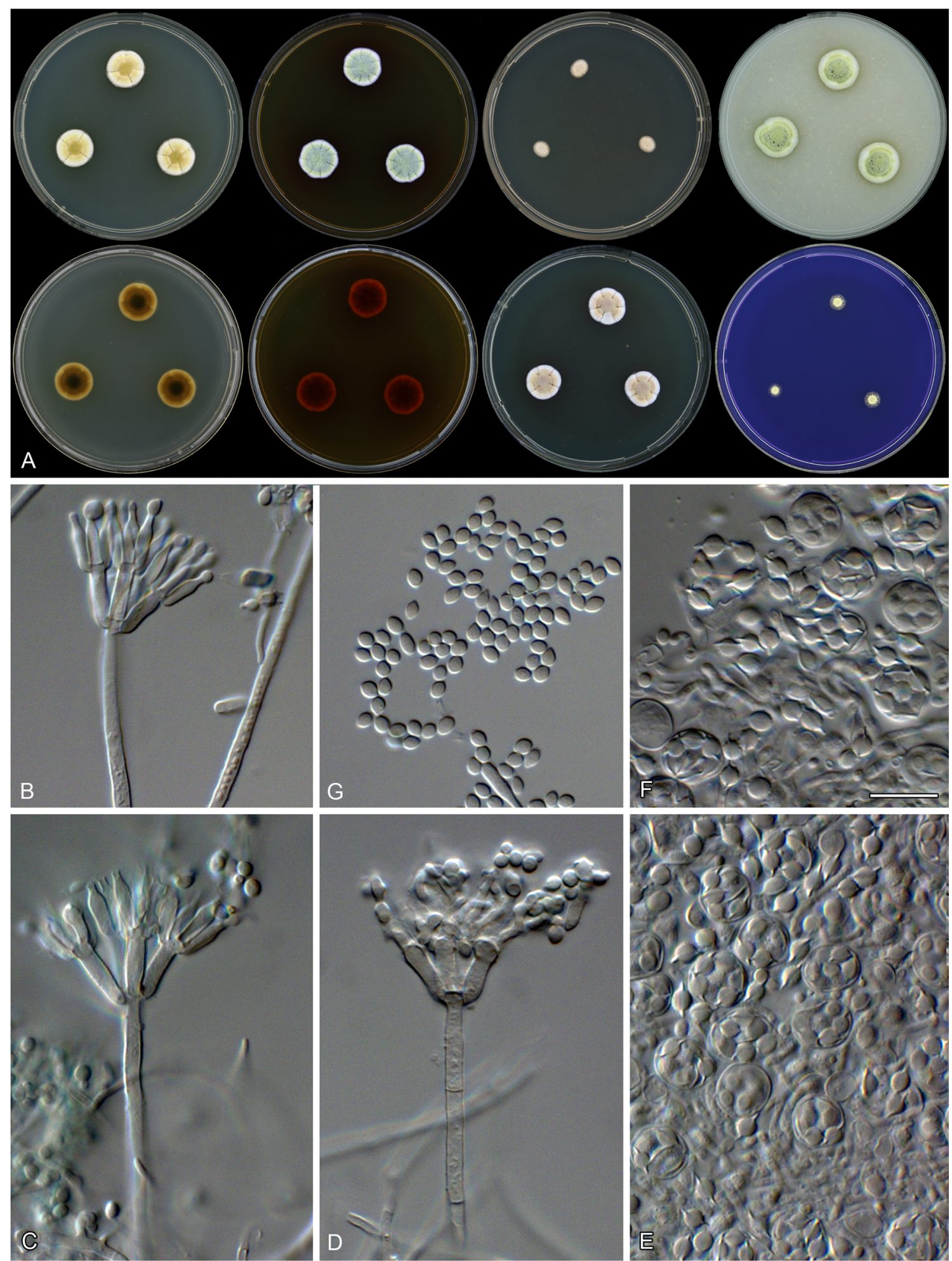

Fig. 3 Morphological characters of Talaromyces columbiensis, CBS Conidiophores. e, f Asci and ascospores. g Conidia. Scale bar: $113151^{\mathrm{T}}$. a Colonies from left to right (top row) CYA, MEA, DG18 and $\mathbf{f}=10 \mu \mathrm{m}$ applies to $\mathbf{b}-\mathbf{g}$ 

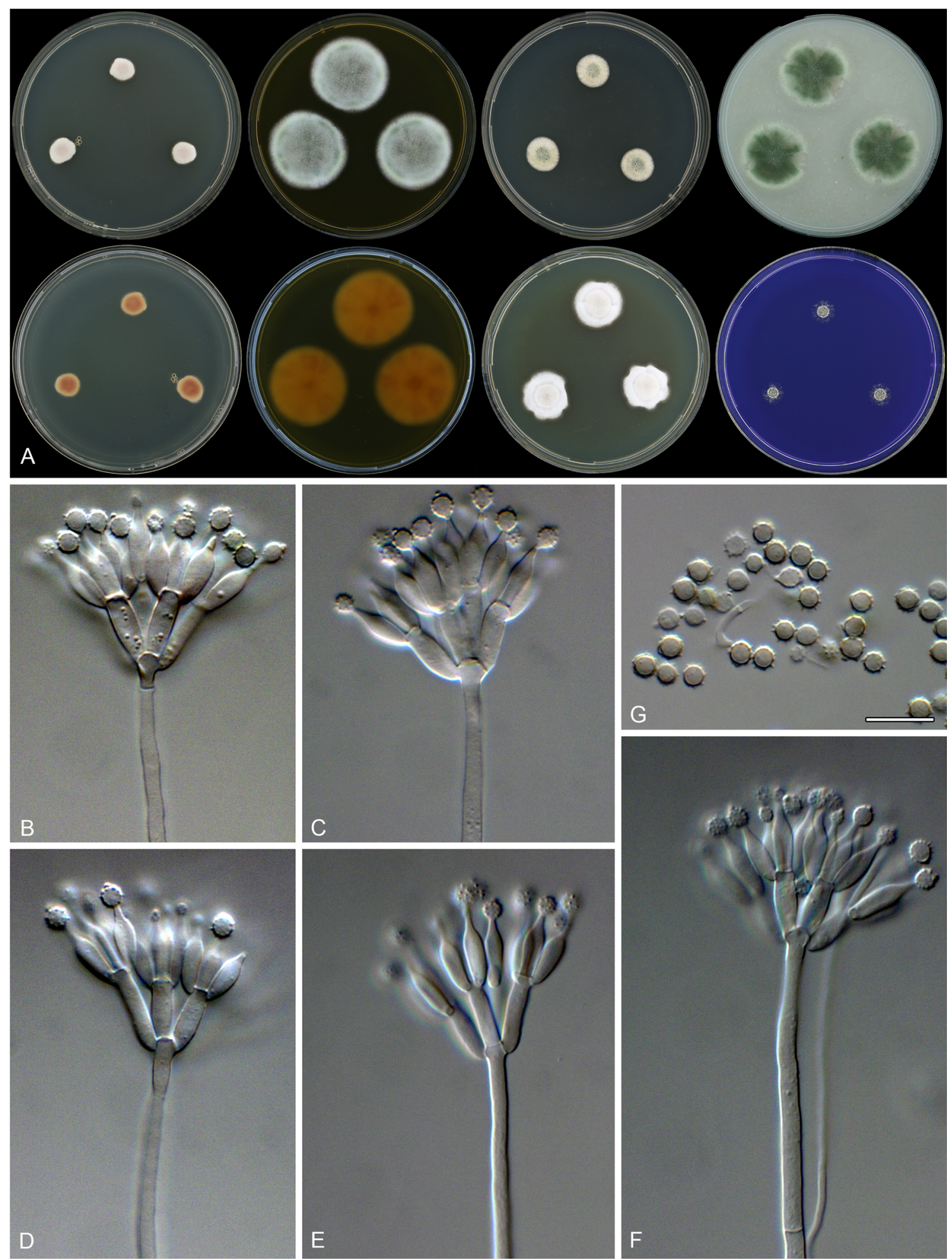

Fig. 4 Morphological characters of Talaromyces francoae, CBS $113134^{\mathrm{T}}$. a Colonies from left to right (top row) CYA, MEA, DG18 and OA; (bottom row) CYA reverse, MEA reverse, YES and CREA. b-f Conidiophores. $\mathbf{g}$ Conidia. Scale bar: $\mathbf{g}=10 \mu \mathrm{m}$ applies to $\mathbf{b}-\mathbf{g}$ 

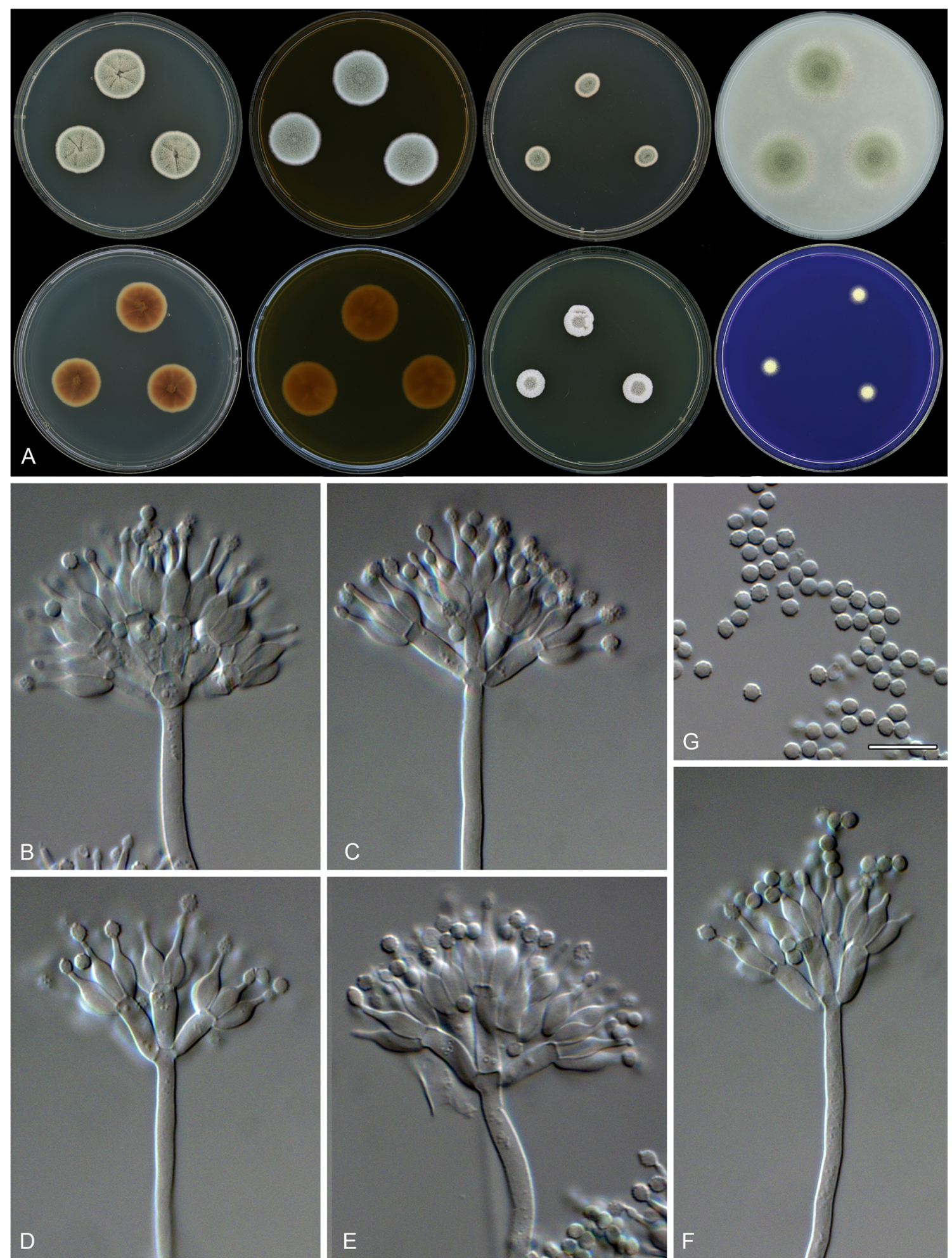

Fig. 5 Morphological characters of Talaromyces purgamentorum, CBS $113145^{\mathrm{T}}$. a Colonies from left to right (top row) CYA, MEA, DG18 and OA; (bottom row) CYA reverse, MEA reverse, YES and CREA. b-f Conidiophores. $\mathbf{g}$ Conidia. Scale bar: $\mathbf{g}=10 \mu \mathrm{m}$ applies to b-g 


\section{Results}

\section{Diversity of Talaromyces species}

ITS barcoding of the isolated fungi revealed the presence of various Talaromyces species among the other fungi isolated from the litterbags. Two known species, T. aculeatus and T. macrosporus, were isolated from the samples, and several other isolates seemed to represent species unknown to science. They are further studied in detail below and described as new species Talaromyces amazonensis, T. columbiensis, T. francoae and T. purgamentorum.

\section{Phylogeny}

The phylogenies presented in Fig. 1 show that the isolates studied here are accommodated in Talaromyces section Talaromyces (i.e., T. amazonensis, T. francoae and T. purgamentorum) and section Bacillispori (T. columbiensis). The concatenated data set was $1348 \mathrm{bp}$ in length (ITS $458 \mathrm{bp}$; BenA and CaM $445 \mathrm{bp}$ ). The Tamura 3-parameter (T92) with gamma distribution $(+\mathrm{G})$ and invariant sites (+I) was found to be the most suitable model for the ML analysis of the combined tree (Fig. 1). For the single gene trees, the T92+G+I model was found to be the most suitable for the ML analysis of the ITS alignment, while the Kimura 2-parameter (K2)+G+I was the most suitable model for both BenA and $C a M$ data sets. ML trees were used to present the phylogenetic data, with bootstrap values (bs) shown near the nodes of the phylogram (Fig. 1). The BenA and CaM data sets had sufficient discriminatory power to differentiate the new species from other recognized species. The ITS barcode of $T$. francoae (CBS $113134^{\mathrm{T}}$ ) was identical to that of T. apiculatus (CBS $\left.312.59^{\mathrm{T}}\right)$.

Talaromyces columbiensis (CBS $113151^{\mathrm{T}}$ ) is located close to T. unicus, and T. francoae (CBS $113134^{\mathrm{T}}$ ) is closely related to T. kendrickii in all phylogenies. Both T. amazonensis (CBS $140373^{\mathrm{T}}$ ) and T. purgamentorum (CBS $113145^{\mathrm{T}}$ ) shift their positions between phylogenies, making it difficult to determine their closest relatives.

\section{Morphology}

The new taxa share similarities with other known species, but can also be differentiated by various characters. Detailed descriptions of the new species are given in the Taxonomy section, and the differences from the other Talaromyces species are summarized in the Discussion. In short, T. amazonensis $\left(\mathrm{CBS} 140373^{\mathrm{T}}\right.$ ) produced yellow ascomata on OA at 25 and $30{ }^{\circ} \mathrm{C}$ after 1-2 weeks of incubation (Fig. 2), and its ascospores resembled those of T. flavus, T. muroii, T. liani and T. thailandensis. Talaromyces columbiensis (CBS $113151^{\mathrm{T}}$ ) produced yellow ascomata on MEA, smooth ascospores with a single equatorial ridge, and has no growth at $37^{\circ} \mathrm{C}$ (Fig. 3). No sexual state was observed in T. francoae (CBS 113134 ${ }^{\mathrm{T}}$ ) or T. purgamentorum (CBS $113145^{\mathrm{T}}$ ). Both species produced ampulliform phialides with a tapering neck and spiny, globose conidia (Figs. 4 and 5). They were not able to grow at $37^{\circ} \mathrm{C}$ and lacked acid production on CREA. Talaromyces
Table 2 Production of extrolites by the Talaromyces species isolated in this study

\begin{tabular}{|c|c|c|}
\hline Species & Culture collection numbers & Extrolites \\
\hline T. aculeatus & IBT $23209=$ DTO 093-F5 & $\begin{array}{l}\text { Altenusin, alternariol, an apolar } \\
\text { dibenzofuran, mitorubrinic acid, } \\
\text { penicillide, purpactin A, talaroderxines }\end{array}$ \\
\hline T. aculeatus & IBT $23210=$ DTO 093-F6 & $\begin{array}{l}\text { Alternariol, mitorubrinic acid, purpactin A, } \\
\text { vermicillin }\end{array}$ \\
\hline T. aculeatus & IBT 23211 = DTO 097-F7 & $\begin{array}{l}\text { Alternariol, mitorubrinic acid, purpactin A, } \\
\text { vermicillin }\end{array}$ \\
\hline T. aculeatus & IBT $23212=$ DTO 093-F8 & $\begin{array}{l}\text { Alternariol, mitorubrinic acid, purpactin A, } \\
\text { vermicillin }\end{array}$ \\
\hline T. amazonensis & CBS $140373^{\mathrm{T}}=\mathrm{IBT} 23215=$ DTO 093-F9 & $\begin{array}{l}\text { berkelic acid, duclauxin, mitorubrinic acid, } \\
\text { vermicillin }\end{array}$ \\
\hline T. amazonensis & IBT $23216=$ DTO 276-H5 & Berkelic acid, duclauxin, mitorubrinic acid \\
\hline T. columbiensis & CBS $113151^{\mathrm{T}}=$ IBT $23206=$ DTO 053-F3 & $\begin{array}{l}\text { A corymbiferan lactone, duclauxin, } \\
\text { mitorubrin, mitorubrinic acid, } \\
\text { wortmannin }\end{array}$ \\
\hline T. francoae & CBS $113134^{\mathrm{T}}=\mathrm{IBT} 23221=$ DTO 056-D9 & $\begin{array}{l}\text { Berkelic acid, mitorubrin, mitorubrinic } \\
\text { acid, vermicillin }\end{array}$ \\
\hline T. macrosporus & CBS $116297=$ IBT 23205 = DTO 189-B9 & A corymbiferan lactone, duclauxin \\
\hline T. purgamentorum & CBS $113145^{\mathrm{T}}=\mathrm{IBT} 23220=\mathrm{DTO} 056-\mathrm{E} 1$ & $\begin{array}{l}\text { A dibenzofuran, penicillide, purpactin } \mathrm{A}, \text { a } \\
\text { shamixanthone, a violaceol }\end{array}$ \\
\hline
\end{tabular}


purgamentorum exhibited restricted growth on DG18 and YES compared to T. francoae.

\section{Extrolites}

The species described here produce various extrolites, all of which are previously found in Talaromyces (Frisvad et al. 1990). Especially common are mitorubrinic acid, alternariol and the penicillides (Table 2). Details on the extrolites found in each species are given in the species descriptions.

\section{Discussion}

This study focused on four novel Talaromyces species isolated from leaf litter in several Colombian lowland rain forests. The multiple gene phylogenies (ITS, BenA and $\mathrm{CaM}$ ) resolved strains into four distinct lineages that represent species. Based on a multigene phylogeny (ITS, BenA and RPB2), Yilmaz et al. (2014) divided the genus into seven clades and provided a sectional classification. Three of the species from this study are located in Talaromyces section Talaromyces, whereas one species (T. columbiensis) falls in section Bacillispori. Previous studies showed that ITS, which is the accepted DNA barcode for fungi (Schoch et al. 2012), is not sufficient to distinguish all Talaromyces species (Yilmaz et al. 2012; Frisvad et al. 2013; Manoch et al. 2013; Yilmaz et al. 2014). As a result, Yilmaz et al. (2014) proposed the use of BenA as a suitable secondary barcode marker for identification of Talaromyces isolates. With the exception of $T$. francoae, however, all newly described species could be identified by using ITS alone. BenA and CaM data sets showed that all novel species are clearly distinct from previously described Talaromyces species.

Visagie et al. (2015) revised Talaromyces species producing ampulliform phialides and rough-walled, globose conidia, and recognized eight species. Except for T. kendrickii, all species could grow at $37^{\circ} \mathrm{C}$. In this study, T. francoae and $T$. purgamentorum have ampulliform phialides and rough-walled, globose conidia. Neither species grows at $37{ }^{\circ} \mathrm{C}$, and neither produces acid on CREA. These two characters of the new species are shared with T. kendrickii. However, on CYA at $25{ }^{\circ} \mathrm{C}$, T. kendrickii (25-31 mm) grows faster than $T$. francoae $(8-10 \mathrm{~mm})$ and T. purgamentorum (19-20 mm). Talaromyces francoae differs from $T$. purgamentorum by their growth rates on CYA and YES. The former species exhibits restricted growth on CYA (8-10 mm) and moderately fast growth on YES (20$22 \mathrm{~mm}$ ), while T. purgamentorum attains a diameter on CYA of $19-20 \mathrm{~mm}$ and $10-12 \mathrm{~mm}$ on YES. Talaromyces amazonensis produces yellow ascomata with spiny, ellipsoidal ascospores, and these characters are common in the genus Talaromyces. Ascospores of T. amazonensis resemble those of T. flavus, T. muroii, T. thailandensis, and T. liani. Both T. flavus and T. muroii grow more restrictedly on CYA than T. amazonensis (9-16 mm vs. 30-38 mm). Talaromyces amazonensis differs from $T$. thailandensis by its ability to grow at $37{ }^{\circ} \mathrm{C}$. The main difference between $T$. liani and T. amazonensis is the ascoma colour. Talaromyces liani has orange-red ascomata, whereas the ascomata of T. amazonensis are yellow. Talaromyces columbiensis produces abundant yellow ascomata and smooth-walled ascospores with a single ridge on MEA after 2 weeks of incubation at $25^{\circ} \mathrm{C}$. This species is phylogenetically closely related to $T$. unicus, which also produces ascospores with a single equatorial ridge. However, T. unicus differs by the production of ascospores with a very rough to spiny wall. Talaromyces stipitatus also produces ellipsoidal, smooth-walled ascospores with a single equatorial ridge. However, this species grows faster on standard agar media (CYA, MEA, OA and YES) and is able to grow on CYA incubated at $37^{\circ} \mathrm{C}$.

Talaromyces is an important genus in biotechnology and in medical and food mycology (Yilmaz et al. 2014). Talaromyces species are isolated worldwide from many kinds of substrates, including house dust, decaying leaves, soil, air, compost, food products, humans and animals. The fungi are considered key players in leaf litter decomposition because of their ability to produce a wide range of extracellular enzymes (de Boer et al. 2005), and some Talaromyces species also produce cellulosedegrading enzymes (Pol et al. 2012; Maeda et al. 2013; Fuji et al. 2014). In this study, we isolated six Talaromyces species from leaf litter in the Colombian Amazon region. Two of them, T. aculeatus and T. macrosporus, have been previously described. The other four species are new to the literature, and thus far found only in decomposed leaf litter in Amazonia, Colombia.

The new Talaromyces species were efficient producers of a series of anticancer compounds. Talaromyces amazonensis in particular produced three different anticancer compounds: duclauxin, berkelic acid and vermicillin. It would be interesting to determine whether these anticancer compounds have a synergistic effect when combined. Another interesting compound found in T. columbiensis was wortmannin, also an anticancer compound, with several additional biological activities.

\section{Taxonomy}

Talaromyces amazonensis Yilmaz, López-Quintero, VascoPal., Frisvad \& Houbraken, sp. nov. Mycobank MB816230. Fig. 2. 
Etymology: From Amazonas, the department from which the species was isolated.

Diagnosis: Moderately fast growth on CYA, MEA, YES and $\mathrm{OA}$ at $25^{\circ} \mathrm{C}$, restricted growth on DG18 at $25^{\circ} \mathrm{C}$, moderate acid production on CREA. Abundant yellow ascomata produced on MEA and OA after 1-2 weeks at $25{ }^{\circ} \mathrm{C}$ with broadly ellipsoidal, thick-walled, spiny ascospores.

Typus: Colombia, dept. Amazonas, Araracuara community in the Middle Caquetá, ex mixed leaves in litterbag, after 6 months of decomposition in a mature forest, isolated in July 2000, C. López-Quintero (holotype HUA 197223; culture ex-type CBS 140373=IBT $23215=$ DTO 093-F9).

ITS barcode: KX011509 (alternative markers: $B e n A=\mathrm{KX} 011490 ;$ CaM=KX011502).

Colony diameter 7 days (mm): CYA 30-38; CYA $30{ }^{\circ} \mathrm{C}$ 35-42; CYA $37^{\circ} \mathrm{C}$ 19-22; MEA 40-45; MEA $30{ }^{\circ} \mathrm{C} 50-55$; DG18 20-25; CYAS No growth; OA 30-45; CREA 12-18; YES 35-42.

Colony characters: CYA $25^{\circ} \mathrm{C}, 7$ days: Colonies slightly raised at centre, slightly sulcate; margins low, plane, entire ( $2 \mathrm{~mm})$; mycelium white and in the centre brownish red due to the pigmentation in reverse; texture floccose; sporulation absent; soluble pigments absent; exudates absent; reverse light yellow (4A4) with dark red (10C8) dots. MEA $25^{\circ} \mathrm{C}, 7$ days: Colonies slightly raised at centre, plane; margins low, plane, entire $(2 \mathrm{~mm})$; mycelium white; texture floccose; sporulation sparse to moderately dense at centre, conidia en masse dull green (27D3); soluble pigments absent; exudates absent; reverse greyish orange (5B6-6B6). YES $25{ }^{\circ} \mathrm{C}, 7$ days: Colonies sunken at centre, slightly sulcate; margins low, plane, entire (2-3 mm); mycelium white, in some parts pastel-red and in the centre yellowish brown (5E4) due to the reverse pigment; texture floccose; sporulation absent; soluble pigments absent; exudates absent; reverse light yellow (4A4) with dark red (10C8) dots. DG18 $25^{\circ} \mathrm{C}, 7$ days: Colonies low, plane; margins low, plane, entire (1-2 mm); mycelium white; texture velvety; sporulation dense, conidia en masse dull green (25D5-26D4); soluble pigments absent; exudates absent; reverse greenish white to greenish grey (28A2-28B2). OA $25{ }^{\circ} \mathrm{C}, 7$ days: Colonies low, plane, yellow ascomata also at $30{ }^{\circ} \mathrm{C}$ abundant; margins low, plane, entire (4-5 mm); mycelium yellow; texture floccose; sporulation absent; soluble pigments absent; exudates absent; reverse pastel-yellow. CREA $25^{\circ} \mathrm{C}, 7$ days: weak growth, moderate acid production.

Micromorphology: Conidiophores biverticillate, sometimes monoverticillate; stipes smooth-walled, 30-220 $\times 2-$ $3 \mu \mathrm{m}$; metulae divergent, two to five, 7.5-12 $\times 2.4-3.8 \mu \mathrm{m}$; phialides acerose, two to five per metula, $8-13 \times 2-3 \mu \mathrm{m}$; conidia smooth-walled, ellipsoidal, 2.5-4(-6) $\times 2-3 \mu \mathrm{m}$. Ascomata bright yellow, globose to subglobose, abundantly ripening within $1-2$ weeks on $\mathrm{OA}$ at $25^{\circ} \mathrm{C}$, covered with a few layers of well-developed networks of yellow hyphae; asci broadly globose to subglobose, 9-13 $\times 8-12 \mu \mathrm{m}$; ascospores broadly ellipsoidal, thick-walled, spiny, 3-5.5 ×2-4 $\mu \mathrm{m}$.

Extrolites: Talaromyces amazonensis produces berkelic acid, duclauxin, mitorubrinic acid and vermicillin. Berkelic acid was first found as an anticancer agent in T. ruber (Stierle et al. 2006). The anticancer agent duclauxin was first found in T. duclauxii, but this compound has also been reported from T. macrosporus (Shibata et al. 1965; Frisvad et al. 1990; Bryant et al. 1993). Duclauxin was also reported from Penicillium herquei and P. manginii (Bryant et al. 1993; Cao et al. 2015), but the strains used had been misidentified, and the producers were Talaromyces species as well. Vermicillin is the third anticancer agent from T. amazonensis (Fuska et al. 1979). Mitorubrinic acid is a common azaphilone metabolite in the genus Talaromyces (Frisvad et al. 1990).

Talaromyces columbiensis Yilmaz, López-Quintero, Vasco-Pal., Frisvad \& Houbraken, sp. nov. Mycobank MB 816231. Fig. 3.

Etymology: From Colombia, the country where the species was isolated.

Diagnosis: Restricted growth on CYA, MEA, YES, OA and DG18 at $25^{\circ} \mathrm{C}$ and no growth at $37^{\circ} \mathrm{C}$. Yellow ascomata abundant on MEA after 2 weeks at $25^{\circ} \mathrm{C}$ with ellipsoidal, smooth, single equatorial ridge ascospores.

Typus: Colombia, Amazonia, Natural Park Amacayacu, ex litterbag containing fresh mixed leaves from mature forest, isolated in September 2004, C. López-Quintero (holotype HUA 197225; cultures ex-type CBS $113151=\mathrm{IBT}$ $23206=$ DTO 058-F3).

ITS barcode: KX011503 (alternative markers: BenA = KX011488; $C a M=\mathrm{KX} 011499)$.

Colony diameter 7 days (mm): CYA 15-17; CYA $30^{\circ} \mathrm{C} 18$; CYA $37{ }^{\circ} \mathrm{C}$ No growth; MEA 15-17; MEA $30{ }^{\circ} \mathrm{C} 16-17$; DG18 5; CYAS 3; OA 15-17; CREA 8-10; YES 14-15.

Colony characters: CYA $25^{\circ} \mathrm{C}, 7$ days: Colonies low, sulcate; margins low, plane, entire (1 mm); mycelium white and yellow; texture floccose; sporulation sparse; soluble pigments absent; exudates absent; reverse yellowish brown (5F5) centre fading to brownish orange to yellowish brown (5C5-5D55E5). MEA $25^{\circ} \mathrm{C}, 7$ days: Colonies raised at centre, sulcate; margins low, plane, entire (1 mm); mycelium dominantly yellow, in the margins white; texture floccose; sporulation sparse, conidia en masse greyish green (28C5-28D5); soluble pigments pale red; exudates absent; reverse brown (7E6) fading to reddish orange (7B7). YES $25^{\circ} \mathrm{C}, 7$ days: Colonies raised at centre, sulcate; margins low, plane, entire (1 mm); mycelium white, brownish orange to light brown (7C5-7D5); texture floccose; sporulation absent to sparse; soluble pigments absent; exudates absent; reverse brownish orange (5C5) centre fading to greyish orange (5B5). DG18 $25^{\circ} \mathrm{C}, 7$ days: Colonies covered with sterile white mycelium; reverse yellowish white (4A2). OA $25^{\circ} \mathrm{C}, 7$ days: Colonies raised at centre, slightly 
sulcate; margins low, plane, entire (1-2 mm), no transparent zone; mycelium white and yellow; texture loosely funiculose to velvety; sporulation moderately dense at centre, conidia en masse dull green (26D4); soluble pigments absent; exudates small, clear droplets; reverse pastel orange-yellow. CREA $25^{\circ} \mathrm{C}, 7$ days: Weak growth, weak acid production.

Micromorphology: Conidiophores biverticillate; stipes smooth-walled, (40-) 50-130 $(-145) \times 2.4-3 \mu \mathrm{m}$; metulae divergent, three to six, $8.5-11.5 \times 2.4-3.5 \mu \mathrm{m}$; phialides acerose, sometimes atypical, two to six per metula, 7$9.5 \times 1.5-2.5 \mu \mathrm{m}$; conidia smooth-walled, ovoid to ellipsoidal, $2.5-3 \times(1.8-) 2-2.5 \mu \mathrm{m}$. Ascomata bright yellow, globose to subglobose, ripening within $1-2$ weeks on OA at $25^{\circ} \mathrm{C}$, covered with layers of well-developed networks of yellow hyphae; asci broadly globose to subglobose, 7-9 $7.5-10 \mu \mathrm{m}$; ascospores ellipsoidal, finely rough to spiny, usually with a single equatorial ridge, $2.5-4.2(-5) \times 2.5-3.5 \mu \mathrm{m}$.

Extrolites: Talaromyces columbiensis produced duclauxin and several related naphthalenones, but also mitorubrins and wortmannin. Wortmannin was originally discovered as an antifungal agent, but it is also a potent enzyme inhibitor of regulatory kinases and is thus an interesting anticancer drug candidate (Wipf and Halter 2005). Wortmannin was originally reported from T. wortmannii and T. flavus (Brian et al. 1957), but these two species are not able to produce wortmannin (Yilmaz et al. 2014). It is thus interesting that $T$. columbiensis can produce this compound. Wortmannin has also been mentioned as a hemorrhagic mycotoxin (Abbas and Mirocha 1998) and an inhibitor of aflatoxin biosynthesis (Lee et al. 2007).

Talaromyces francoae Yilmaz, López-Q., Vasco-Pal. \& Houbraken, sp. nov. Mycobank MB 816232. Fig. 4.

Etymology: named after Franco, the family name of Dr. Ana Esperanza Franco-Molano, who made major contributions to Colombian mycology.

Diagnosis: Conidiophores biverticillate with ampulliform phialides that taper to a very thin neck producing roughwalled, verrucose conidia. Lack of acid production on CREA and absence of growth on CYA at $37{ }^{\circ} \mathrm{C}$. Restricted growth on CYA at $25^{\circ} \mathrm{C}(8-10 \mathrm{~mm})$.

Typus: Colombia, Dept. Amazonas, Peña Roja, ex leaf litter from 4-month old litterbag in Pseudomonotes tropenbosii (Dipterocarpaceae) forest, isolated in March 2000, C. López-Quintero (holotype HUA 197224; culture ex-type CBS 113134=IBT 23221 = DTO 056-D9).

ITS barcode: KX011510 (alternative markers: $B e n A=\mathrm{KX} 011489 ; C a M=\mathrm{KX} 011501)$.

Colony diameter 7 days (mm): CYA 8-10; CYA $30^{\circ} \mathrm{C} 29-30$; CYA $37^{\circ} \mathrm{C}$ No growth; MEA 20-21; MEA $30^{\circ} \mathrm{C} 37-38$; DG18 10-11; CYAS No growth; OA 35-37; CREA 5-9; YES 20-22.

Colony characters: CYA $25^{\circ} \mathrm{C}, 7$ days: Colonies raised at centre, slightly sulcate; margins low, plane, entire ( $2 \mathrm{~mm})$; mycelium white; texture floccose; sporulation moderately dense, conidia en masse dull to greyish green (25D4-25D5); soluble pigments absent; exudates absent; reverse pale orange (5A3-6A3). MEA $25^{\circ} \mathrm{C}, 7$ days: Colonies raised, slightly sulcate; margins low, plane, entire $(2 \mathrm{~mm})$; mycelium white; texture floccose and velvety; sporulation dense, conidia en masse dull to greyish green (26D4-27D4); soluble pigments absent; exudates absent; reverse greyish orange (5B6) with reddish brown (8D8) dots and circle. YES $25{ }^{\circ} \mathrm{C}, 7$ days: Colonies raised at centre, sulcate; margins low, plane, entire ( $2 \mathrm{~mm}$ ); mycelium white; texture floccose; sporulation absent to sparse; soluble pigments absent; exudates absent; reverse brownish red (8C8) centre fading to light orange (5A4). DG18 $25{ }^{\circ} \mathrm{C}, 7$ days: Colonies sterile, raised, plane; margins low, plane, entire ( $2 \mathrm{~mm}$ ); mycelium white; texture floccose; sporulation absent to sparse; soluble pigments absent; exudates clear droplets; reverse light orange (5A4). OA $25^{\circ} \mathrm{C}, 7$ days: Colonies low, plane; margins low, plane, entire (3-4 mm); mycelium white; texture velvety; sporulation moderately dense to dense, conidia en masse greyish green (26D526E5); soluble pigments absent; exudates absent; reverse pastel-red in centre fading to beige (at $30{ }^{\circ} \mathrm{C}$ violet red). CREA $25^{\circ} \mathrm{C}, 7$ days: weak growth, acid production absent.

Micromorphology: Conidiophores biverticillate; stipes smooth-walled, $125-450 \times 2.2-3 \mu \mathrm{m}$; metulae divergent, 3$6,8-13 \times 2.5-4.5 \mu \mathrm{m}$; phialides ampulliform, tapering to a very thin neck, $3-6$ per metula, $8.5-12 \times 2.5-4 \mu \mathrm{m}$; conidia verrucose, rough-walled, globose, $2.5-4 \times 2.5-4 \mu \mathrm{m}$.

Extrolites: Talaromyces francoae produces berkelic acid, mitorubrin, mitorubrinic acid and vermicillin.

Talaromyces purgamentorum Yilmaz, López-Quintero, Vasco-Pal. \& Houbraken, sp. nov. Mycobank MB 816233. Fig. 5.

Etymology: named after de original substrate of the type strain, decomposed leaf litter debris.

Diagnosis: Conidiophores biverticillate with ampulliform phialides that taper to a very thin neck producing roughwalled, verrucose conidia. Lack of acid production on CREA and absence of growth on CYA at $37^{\circ} \mathrm{C}$. Restricted growth on YES (10-12 mm) and DG18 (5-6 mm) at $25^{\circ} \mathrm{C}$.

Typus: Colombia, dept. Amazonas, Peña Roja, ex mixed leaf litter from 4 months old litterbag in Pseudomonotes tropenbosii (Dipterocarpaceae) forest, isolated in March 2000, C. López-Quintero (holotype HUA 197222; culture ex-type CBS 113145=IBT $23220=$ DTO 056-E1).

ITS barcode: KX011504 (alternative markers: $B e n A=\mathrm{KX} 011487 ; C a M=\mathrm{KX} 011500)$.

Colony diameter, 7 days (mm): CYA 19-20; CYA $30^{\circ} \mathrm{C}$ 24-25; CYA $37^{\circ} \mathrm{C}$ No growth; MEA 20-22; MEA $30^{\circ} \mathrm{C} 25$ 28; DG18 5-6; CYAS 2-3; OA 33-35; CREA 7-10; YES $10-12$.

Colony characters: CYA $25^{\circ} \mathrm{C}, 7$ days: Colonies raised at centre, sunken at centre, sulcate; margins low, plane, entire $(1 \mathrm{~mm})$; mycelium white; texture loosely funiculose and 
velvety; sporulation dense, conidia en masse dull green (26D4-26E4); soluble pigments absent; exudates absent; reverse brown (6E7) centre reddish brown fading to greyish yellow (8D6 and 4B5). MEA $25{ }^{\circ} \mathrm{C}, 7$ days: Colonies low, slightly sulcate; margins low, plane, entire (1-2 mm); mycelium white; texture velvety; sporulation dense, conidia en masse dull green (26D4-26E4); soluble pigments absent; exudates absent; reverse brownish orange (5C6-6C6). YES $25{ }^{\circ} \mathrm{C}, 7$ days: Colonies slightly raised, sterile white aerial mycelium, slightly sulcate; margins low, plane, entire $(<1 \mathrm{~mm})$; mycelium white; texture floccose and funiculose; sporulation absent to sparse; soluble pigments absent; exudates absent; reverse bronze brown (5E5) centre fading to greyish orange (5B5). DG18 $25^{\circ} \mathrm{C}, 7$ days: Colonies slightly raised, plane; margins low, plane, entire $(<1 \mathrm{~mm})$; mycelium white; texture velvety; sporulation dense, conidia en masse dull green (26D4-26E4); soluble pigments absent; exudates absent; reverse light brown (5D4-5D5). OA $25{ }^{\circ} \mathrm{C}, 7$ days: Colonies low, plane; margins low, plane, entire (4-5 mm); mycelium white; texture velvety; sporulation moderately dense, conidia en masse dull green (28D4); soluble pigments absent; exudates absent; reverse pastel red. CREA $25^{\circ} \mathrm{C}$, 7 days: Weak growth, acid production absent.

Micromorphology: Conidiophores biverticillate; stipes smooth-walled, $170-300 \times 2.8-4.2 \mu \mathrm{m}$; metulae divergent, $3-6,7-11.5 \times 3-4.5 \mu \mathrm{m}$; phialides ampulliform, tapering to a very thin neck, 3-6 per metulae, $7.5-12.5 \times 3-4 \mu \mathrm{m}$; conidia rough-walled, globose to subglobose, $2-3.3 \times 2-3 \mu \mathrm{m}$.

Extrolites: Talaromyces purgamentorum produces a dibenzofuran, penicillide, purpactin $\mathrm{A}$, a shamixanthone and a violaceol. The dibenzofuran had the same UV spectrum as karnatakafurans A and B (Manniche et al. 2004), but was more apolar. Penicillide and purpactins (also called vermixocins) are related extrolites that have been isolated from several Talaromyces species, including T. derxii, T. purpurogenus and T. flavus (Sassa et al. 1974; Suzuki et al. 1991; Proksa et al. 1992). These compounds have very high levels of bioactivity, and are inhibitors of acylCoA:cholesterol acyltransferases and calpain (Tomoda et al. 1991; Chung et al. 1998).

Acknowledgments This research was supported in part by NWOWOTRO grants 895.100.014 and WB 84-525. Aida Vasco received grants from The Netherlands Fellowship Programmes (NFP) of the Netherlands organization for international cooperation in higher education (NUFFIC), The Faculty for the Future of Schlumberger Foundation (FFTF Grant 2011-2013) and The International Foundation of Science (IFS Grant D/5052-1, 2011-2-13f). Further financial support from the Studienstiftung Mykologie and the CBS-KNAW is greatly appreciated. Logistical support and collection permission was given by Tropenbos Colombia, and we thank Dr. Carlos Rodríguez for this. Uwe Braun is thanked for his advice on the new species names. Finally, we want to thank the indigenous people and the workers in the Parque Natural Nacional Amacayacu, Araracuara and Meta for their willingness to collaborate in this study.
Open Access This article is distributed under the terms of the Creative Commons Attribution 4.0 International License (http:// creativecommons.org/licenses/by/4.0/), which permits unrestricted use, distribution, and reproduction in any medium, provided you give appropriate credit to the original author(s) and the source, provide a link to the Creative Commons license, and indicate if changes were made.

\section{References}

Abbas HK, Mirocha CJ (1998) Isolation and purification of hemorrhagic factor (wortmannin) from Fusarium oxysporum (N17B). Appl Environ Microbiol 54:1268-1274

Brian PW, Curtis PJ, Hemming HG, Norris GLF (1957) Wortmannin, an antibiotic produced by Penicillium wortmannii. Trans Br Mycol Soc 40:365-368

Bryant FO, Cutler HG, Jacyno JM (1993) Properties and cost-effective method for production of the antitumor agent duclauxin from sporulation Penicillium herquei. J Pharm Sci 82:1214-1217

Cao P, Yang J, Miao C-P, Uan Y, Ma Y-T, Li X-N, Zhao L-X, Huang S-X (2015) New duclauxamide from Penicllium manginii YIM PH30375 and structure revision of the duclauxin family. Org Lett 17:1146-1149

Chung M-C, Lee H-J, Chun H-K, Kho Y-H (1998) Penicillide, a nonpeptide calpain inhibitor, produced by Penicillium sp. F60760. J Microbiol Biotechnol 8:188-190

de Boer W, Folman LB, Summerbell RC, Boddy L (2005) Living in a fungal world: impact of fungi on soil bacterial niche development. FEMS Microbiol Rev 29:795-811

Frisvad JC, Filtenborg O, Samson RA, Stolk AC (1990) Chemotaxonomy of the genus Talaromyces. Antonie Van Leeuwenhoek 57:179-189

Frisvad JC, Yilmaz N, Thrane U, Rasmussen KB, Houbraken J, Samson RA (2013) Talaromyces atroroseus, a new species efficiently producing industrially relevant red pigments. PLoS ONE 8:e84102

Fuji T, Hoshino T, Inoue H, Yano S (2014) Taxonomic revision of the cellulose degrading fungus Acremonium cellulolyticus nomen nudum to Talaromyces based on phylogenetic analysis. FEMS Microbiol Lett 351:32-41

Fuska J, Nemec P, Fusková A (1979) Vermicillin, a new metabolite from Penicillium vermiculatum inhibiting tumor cells in vitro. J Antibiot 32:667-669

Houbraken J, López-Quintero CA, Frisvad JC, Boekhout T, Theelen B, Esperanza Franco-Molano A, Samson RA (2011) Penicillium araracuarense sp. nov., Penicillium elleniae sp. nov., Penicillium penarojense sp. nov., Penicillium vanderhammenii sp. nov. and Penicillium wotroi sp. nov., isolated from leaf litter. Int J Syst Evol Microbiol 61:1462-1475

Houbraken J, Spierenburg H, Frisvad JC (2012) Rasamsonia, a new genus comprising thermotolerant and thermophilic Talaromyces and Geosmithia species. Antonie Van Leeuwenhoek 101:403-421

Kildgaard S, Mansson M, Dosen I, Klitgaard A, Frisvad JC, Larsen TO, Nielsen KF (2014) Accurate dereplication of bioactive secondary metabolites from marine-derived fungi by UHPLC-DADQTOFMS and MS/HRMS library. Mar Drugs 12:3681-3705

Klitgaard A, Iversen A, Andersen MR, Larsen TO, Frisvad JC, Nielsen KF (2014) Aggressive dereplication using UHPLC-DAD-QTOFscreening extracts for up to 3000 fungal secondary metabolites. Anal Bioanal Chem 406:1933-1943

Kornerup A, Wanscher JH (1967) Methuen handbook of colour. Methuen \& Co Ltd, Copenhagen

Lee J-W, Roze LV, Linz JE (2007) Evidence that a wortmannin-sensitive signal transduction pathway regulates aflatoxin biosynthesis. Mycologia 99:562-568 
López-Quintero CA, Straatsma G, Franco-Molano AE, Boekhout T (2012) Macrofungal diversity in Colombian Amazon forests varies with regions and regimes of disturbance. Biodivers Conserv 21: 2221-2243

López-Quintero CA, Atanasova L, Esperanza Franco-Molano A, Gams W, Komon-Zelazowska M, Theelen B, Müller WH, Boekhout T, Druzhinina I (2013) DNA barcoding survey of Trichoderma diversity in soil and litter of the Colombian lowland Amazonian rainforest reveals Trichoderma strigosellum sp. nov. and other species. Antonie Van Leeuwenhoek 104:657-674

Maeda RN, Barcelos CA, Santa Anna LM, Pereira N Jr (2013) Cellulase production by Penicillium funiculosum and its application in the hydrolysis of sugar cane bagasse for second generation ethanol production by fed batch operation. J Biotechnol 163:38-44

Maggs J (1985) Litter fall and retranslocation of nutrients in a refertilized and prescribed burned Pinus elliottii plantation. For Ecol Manag 12: 253-268

Manniche S, Sprogøe K, Dalsgaard PW, Christophersen C, Larsen TO (2004) Karnatakafurans A and B: two dibenzofurans isolated from the fungus Aspergillus karnatakaensis. J Nat Prod 67:2111-2112

Manoch L, Dethoup T, Yilmaz N, Houbraken J, Samson RA (2013) Two new Talaromyces species from soil in Thailand. Mycoscience 54: 335-342

Pol D, Laxman RS, Rao M (2012) Purification and biochemical characterization of endoglucanase from Penicillium pinophilum MS 20. Indian J Biochem Biophys 49:189-194

Proksa B, Uhrín D, Adamcová J, Fuska J (1992) Vermixocins A and B, two novel metabolites from Penicillium vermiculatum. J Antibiot 45:1268-1272

Romero SM, Romero AI, Barrera V, Comerio R (2016) Talaromyces systylus, a new synnematous species from Argentinean semi-arid soil. Nova Hedwigia 102:241-256

Samson RA, Yilmaz N, Houbraken J, Spierenburg H, Seifert KA, Peterson SW, Varga J, Frisvad JC (2011) Phylogeny and nomenclature of the genus Talaromyces and taxa accommodated in Penicillium subgenus Biverticillium. Stud Mycol 70:159-183

Sassa T, Niwa G, Unno H, Ikeda M, Miura Y (1974) Structure of penicillide, a new metabolite produced by a Penicillium sp. Tetrahedron Lett 15:3941-3942

Schoch CL, Seifert KA, Huhndorf S, Robert V, Spouge JL, Lévesque CA, Chen W, Fungal Barcoding Consortium (2012) Nuclear ribosomal internal transcribed spacer (ITS) region as a universal DNA barcode marker for Fungi. PNAS 109:6241-6246

Shibata S, Ogihara Y, Tokutake N, Tanaka O (1965) Duclauxin, a metabolite of Penicillium duclauxii (Delacroix). Tetrahedron Lett 6:12871288
Smedsgaard J (1997) Micro-scale extraction procedure for standardized screening of fungal metabolite production in cultures. J Chromatogr A 760:264-270

Stierle AA, Stierle DB, Kelly K (2006) Berkelic acid, a novel spiroketal with selective anticancer activity from an acid mine waste fungal extremophile. J Org Chem 71:5357-5360

Suzuki K, Nozawa K, Usagawa S, Nakajima S, Kawai K (1991) Penicillide and dehydropenicillide from Talaromyces derxii. Phytochemistry 30:2096-2098

Tamura K, Stecher G, Peterson D, Filipski A, Kumar S (2013) MEGA6: molecular evolutionary genetics analysis version 6.0. Mol Biol Evol 30:2725-2729

Tomoda H, Nishida H, Masuma R, Cao J, Okuda S, Omura S (1991) Purpactins, new inhibitors of acyl-CoA:cholesterol acyltransferase produced by Penicillium purpurogenum. I. Production, isolation and physico-chemical and biological properties. J Antibiot 44:136-143

Vasco-Palacios AM, Franco-Molano AE (2013) Diversity of Colombian macrofungi (Ascomycota-Basidiomycete). Mycotaxon 121:499

Vasco-Palacios AM, López-Quintero C, Franco-Molano AE, Boekhout T (2014) Austroboletus amazonicus sp. nov. and Fistulinella campinaranae var. scrobiculata, two commonly occurring boletes from a forest dominated by Pseudomonotes tropenbosii (Dipterocarpaceae), in Colombian Amazonia. Mycologia 106: 1004-1014

Visagie CM, Houbraken J, Frisvad JC, Hong S-B, Klaassen CHW, Perrone G, Seifert KA, Varga J, Yaguchi T, Samson RA (2014) Identification and nomenclature of the genus Penicillium. Stud Mycol 78:343-371

Visagie CM, Yilmaz N, Frisvad JC, Houbraken J, Seifert KA, Samson RA, Jacobs K (2015) Five new Talaromyces species with ampulliform-like phialides and globose rough walled conidia resembling T. verruculosus. Mycoscience 56:486-502

Wang QM, Zhang YH, Wang B, Wang L (2016) Talaromyces neofusisporus and T. qii, two new species of section Talaromyces isolated from plant leaves in Tibet, China. Sci Rep 6:18622

Wipf P, Halter RJ (2005) Chemistry and biology of wortmannin. Org Biomol Chem 3:2053-2061

Yilmaz N, Houbraken J, Hoekstra ES, Frisvad JC, Visagie CM, Samson RA (2012) Delimitation and characterisation of Talaromyces purpurogenus and related species. Persoonia 29:39-54

Yilmaz N, Visagie CM, Houbraken J, Frisvad JC, Samson RA (2014) Polyphasic taxonomy of the genus Talaromyces. Stud Mycol 78: 175-342

Yilmaz N, Visagie CM, Frisvad JC, Houbraken J, Jacobs K, Samson RA (2016) Taxonomic re-evaluation of species in Talaromyces section Islandici, using a polyphasic approach. Persoonia 36:37-56 